\title{
Evaluation of Official Governmental (e-Government) Websites for Accessibility in the Middle East
}

\author{
Memen Salihi \\ Khazar University \\ 41 Mehseti Street \\ Baku, Azerbaijan
}

\author{
Mahammad Sharifov \\ Khazar University \\ 41 Mehseti Street \\ Baku, Azerbaijan
}

\author{
Abdulsalam S. Mustafa \\ 41 Mehseti Street \\ Baku, Azerbaijan
}

\begin{abstract}
World Wide Web (www), a digital platform providing access to information in an accessible and equitable manner offers immense opportunities to all categories of users. Its inclusivism enables people with physical challenges to access websites, identify, appreciate, navigate, utilize, interact and contribute to the web. This study evaluates the web accessibility features of 58 governmental websites of 17 countries in the Middle East by means of the manual and the automated testing methods with different benchmarks based on the Web Content Accessibility Guidelines 2.0 (WCAG) and Section 508 standards for the website accessibility, for each to achieve a more comprehensive and efficient result for better analysis. The results of the findings are contrasting; from the manual evaluation based on specific criteria, countries such as United Arab Emirates, Saudi Arabia, Bahrain and Oman scored high percentages in majority of the criteria but scored very low in the automated evaluation.
\end{abstract}

\section{Keywords}

accessibility, e-government, physically challenged users, websites, web-accessibility.

\section{INTRODUCTION}

Recently, the internet has become the main repository of information because it facilitates information acquisition and dissemination globally. The internet also enables citizens use government services online as a part of daily activities, therefore, Information and Communication Technology (ICT) and most especially the internet has become central to daily life, living and activities as it provides access to information and open data.

The questions in this research include:

Q1: Are government website accessible to users with disabilities to enable them fully utilize website or not?

Q2: What percentage of the citizens are aware that government websites provide support for disabled users?

E-government can be defined as effectively utilizing ICT tools by government for improved service delivery and timely dissemination of information to citizens. The e-government services should be able to identify user requirements before developing a website while making it accessible to everyone including people with disabilities [2]. A review conducted by the office of Disability Studies, UK, shows that one of the main concerns of people with disability is access to government websites and online services [3].

This highlights the fact that government websites are expected to be equally accessible to everyone just as it affirms the United Nations Assembly enactment, in 2006, of the Treaty on Rights of Disabled that guarantee the equal accessibility for people with disability to Information and Communication Technology [2], [3].

The Word Wide Web Consortium (W3C) provide guidelines and standards for the website to offer equal access to everyone but in some countries like Australia, Canada and United States, those guidelines are applied in form of National Transition Strategy (NTS) the Section 508 Workforce Rehabilitation Act of 1973, [5] and the BS 8878 Web Accessibility Code of Practice [6]. In contrast, there is lack of awareness on web accessibility in most of countries in the Middle East especially the gulf region as observed in studies by Al-Khalifa [3] and Kamoun [7].

\section{LITERATURE REVIEW}

Web accessibility, according to World Wide Web Consortium (W3C) is "that people with disabilities can perceive, understand, navigate, and interact with the Web, and that they can contribute to the Web" [8]. Akgul \& Vatansever [9] state that web accessibility can be defined as the degree to which a website is accessible to the largest possible range of people. They revealed that the accessibility of a web site is dependent on the number of people who are able to access it; the more people are able to access a website; the site becomes more accessible [9].

The World Wide Web (W3) project established by Lee in 1989 was aimed at making information more accessible and useful to people around the world. Lee and Fischetti, [10] envisioned the web as a tool which will be used for communicating, and web access enables users to "discover what other people mean and where they are coming from".

Conversely, the main goal of World Wide Web project is to make the internet accessible to everyone but users with disabilities are unable to easily access information online thereby necessitating the development of Web Accessibility to enable users with disabilities access the web. The Web Accessibility project launched in 1996 by W3C [11] was not successful at the initial stage of deployment due a lack of standard guidelines which limited the ability of users and programmers. The legacy version of Web Accessibility mainly focused on the standard guidelines, ideas, and educational tools. Web Accessibility Initiative (WAI) was developed as a standard guideline for web designers, web authors, web developers and end users to enable websites, videos, and other software be highly useful to the users [13].

$\mathrm{W} 3 \mathrm{C}$ is a non-profit international group which brings member organizations, staff, and the public together to collaborate and develop standards that make Web pages accessible to Internet technologies users now and in future [14]. Within its broader mission, the W3C has a Web Accessibility Initiative (WAI) 
that contains a set of Web content accessibility guidelines to assist creators of Web pages in developing sites with features that offer access to individuals with disabilities.

To make websites more accessible, W3C established a list of guidelines and standards in the implementation of technology for website accessibility. These standards are applicable when it is appropriate at any level, either local or national.

Different stakeholders including organizations, industries and governments assist the $\mathrm{W} 3 \mathrm{C}$ to improve the standards and guidelines for more accessible information to citizens including the users with disabilities such as loss of vision, loss of hearing and physical impairment, among other disabilities [12]. Additionally, it has become imperative to develop websites with accessibility features. However, without proper guidelines for web accessibility, there are profound challenges for web designers and developers arising from design and development of accessible enabled websites.

From the perspectives of the Middle East countries, the dearth of researches in this area has prompted the need for this research. Also, Middle East countries totaling 17 in number, and majority of which are Arabian, do not have strong or existing laws and policies to support people with disabilities. Hence, this study is investigating the extent to which these countries are making efforts to applying the accessibility guidelines to governmental website and online services. Furthermore, the paper will show the evaluation result using two methods.

\section{RESEARCH METHODOLOGY}

A total of 85 e-governmental websites from the 17 countries in the Middle East were selected for evaluation. This includes the top five websites from each country based on highest number of visits by users (hits). This study applies quantitative techniques by using the automated checking tool to determine the accessibility of government websites in the Middle East. Additionally, manual testing containing a set of criteria ranked in order of importance is used in evaluating the websites. All the criteria used in evaluating the websites are in line with the WCAG 2.0 standards. The five governmental websites evaluated include e-government portal; websites of the ministries of High Education; Education; Health; Labor and Social Development from each of the 15 countries in the Middle East.

These countries are Bahrain, Cyprus, Egypt, Iran, Iraq, Israel, Jordan, Kuwait, Lebanon, Oman, Palestine, Qatar, Saudi Arabia, Syria, Turkey, United Arab Emirates (UAE) and Yemen.

SortSite an online tool that provides a complete report on the accessibility, errors, compatibility and standard of websites was employed to test the various websites is used for the automated testing. The focus area of this evaluation was on Accessibility and Standards as shown in figure 1.

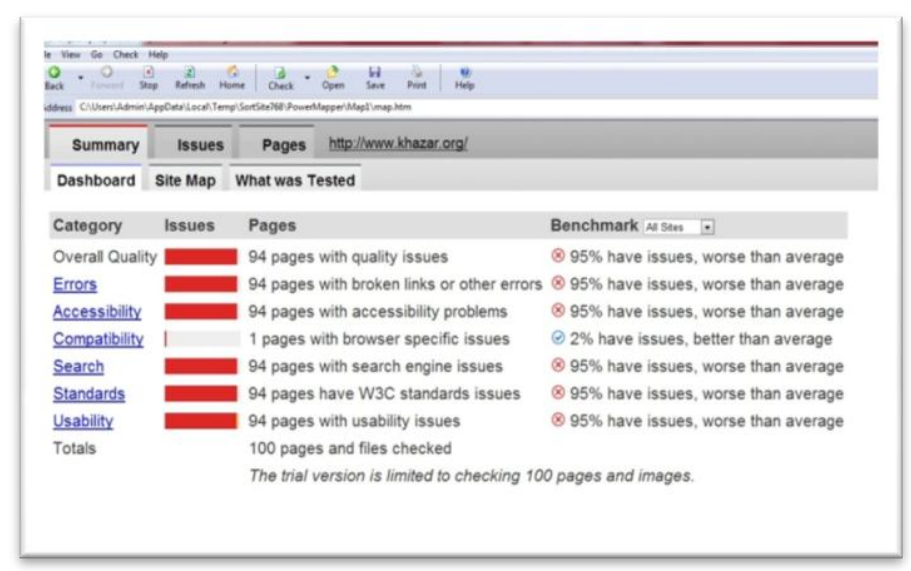

Fig.1: SortSide tool report

SortSite was used in evaluating the website because of its ability in appraising the entire website in addition to providing complete report and analysis on errors on the website including Server configuration; Content issues (English United States of America Spelling format); Blocked links; User defined errors; HTTP status codes and Script errors [16]. Correspondingly, it will evaluate web accessibility that include Section 508 of the Rehabilitation Act; Web Content Accessibility Guidelines 2.0 (WCAG 2.0) levels A, AA and AAA as detailed in table 1; NVDA Accessibility support, Voice-Over Accessibility support and Window-Eyes accessibility support. Furthermore, SortSite assesses the standards for W3C CSS validation, W3C deprecated features, W3C HTML and HTML5 validation.

Table 1. WAI Conformance

\begin{tabular}{|l|l|}
\hline Conformance level & Description \\
\hline Priority A & $\begin{array}{l}\text { All priority 1 checkpoints are met. } \\
\text { This is the minimum (basic) W3C } \\
\text { requirement. Otherwise, one or two } \\
\text { more groups of people will find it } \\
\text { impossible to access information } \\
\text { from the website. This is a minimum } \\
\text { requirement and must be met }\end{array}$ \\
\hline Priority AA & $\begin{array}{l}\text { All priority 1 and 2 checkpoints are } \\
\text { satisfied; otherwise, one or more } \\
\text { groups of people will find it difficult } \\
\text { to access information from the } \\
\text { website. And this level should be met } \\
\text { because it removes the barriers to } \\
\text { accessing the documents. }\end{array}$ \\
\hline Priority AAA & $\begin{array}{l}\text { All priority 1, 2 and 3 checkpoints are } \\
\text { satisfied; otherwise, one or more } \\
\text { groups of people will find it somehow } \\
\text { difficult to access information from } \\
\text { the website. This conformance level } \\
\text { may be addressed by web developer } \\
\text { to access the documents. }\end{array}$ \\
\hline
\end{tabular}

The above table indicates the priority, description and symbols displayed on the website if the last satisfies the description; while one or more groups of users will find it 
difficult to access information in the document if none of the guidelines is met [1]. In the manual evaluation, shown in figure 2, Web Accessibility Toolbar is used to evaluate the websites while considering specific significant criteria for website accessibility without the use of Assistive Technologies. These criteria include font adjustment, language support, print version, application support, color standards, B-chromatic version (B/W version), and accessibility help.

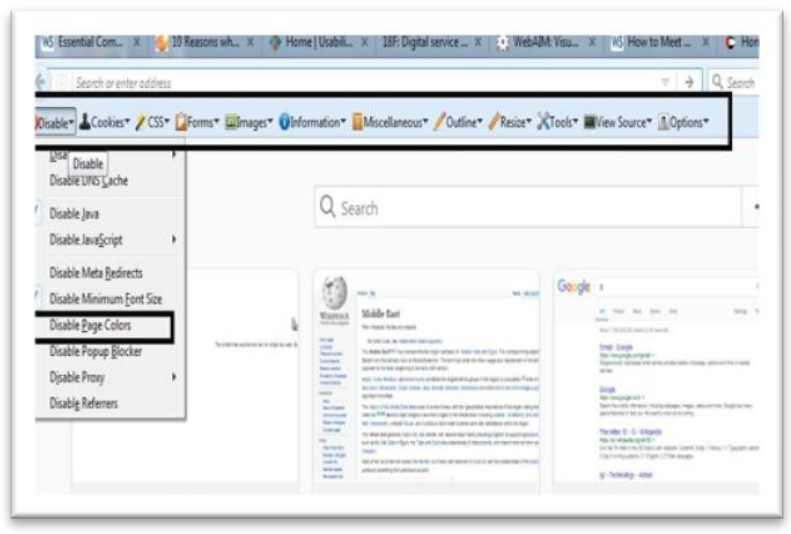

Fig.2: Web Accessibility Toolbar (WAT)

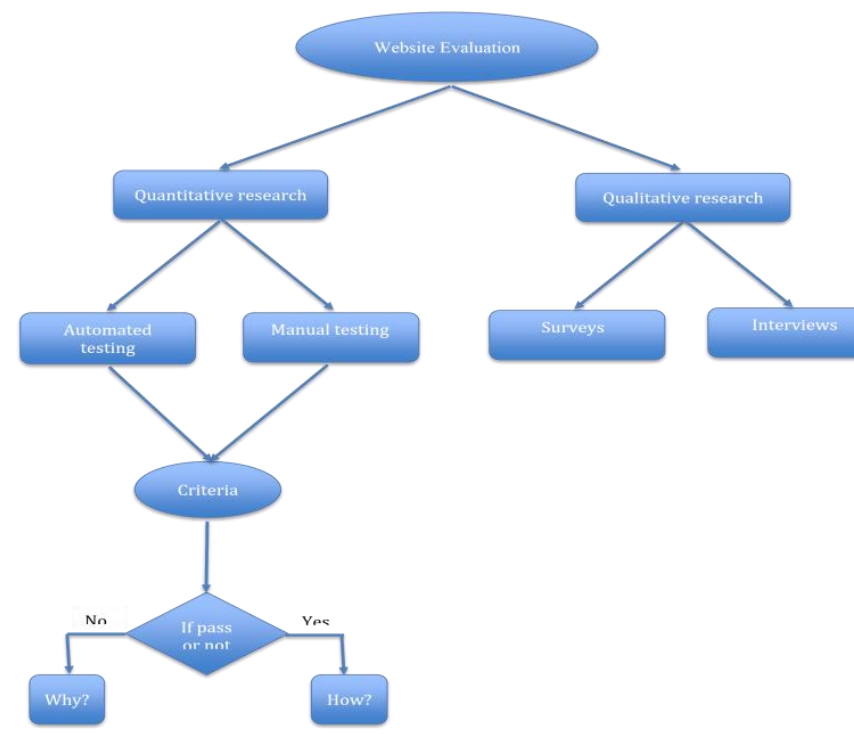

Fig.3: Research Design for the study

\subsection{Research Design}

Research design can be described as an arrangement of settings for the gathering and analyzing of data by combining relevance to research with economy in practice. The second aspect related to this guarantees that "the measures undertaken are sufficient to attain a valid, unbiased and precise answers to the research questions" [12].

\subsection{Evaluation Procedure}

The evaluation procedure for the automated evaluation is done by copying and pasting the link of a specific website in the SortSide tool address bar to examine the website. Clicking on the check button will prompt the tool to evaluate the entire website and determine which sections of the site contains errors and keeps count of the number of errors. The website will pass the accessibility test if it meets the requirements of
WCAG 2.0. On completion of the test, the test tool displays a comprehensive report that contains information on errors; accessibility; compatibility; standards and usability as presented in figure 1 .

For the automated evaluation, an excel sheet was initially created with columns for each criterion containing font adjustment; language support; print version; application support; color standards; B-chromatic version (B/W version); and accessibility help. Additionally, a list was developed containing all five ministries which will be evaluated for all 17 countries. Included in the list are Ministry of Health; Ministry of Education; Ministry of Higher Education; Ministry of Labor; and the Government e-Portal. Furthermore, all websites were individually evaluated to determine if they meet the criteria or not. Lastly, the results of each country were summarized in separate tables as shown in table 2 while each benchmark was allocated marks and computed for each country to generate a single chart with percentages.

Table 2. Sample result of Manual Evaluation for Bahrain

\begin{tabular}{|c|c|c|c|c|c|}
\hline $\begin{array}{c}\text { E- } \\
\text { Government }\end{array}$ & 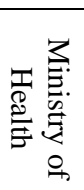 & 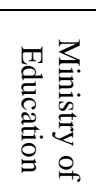 & 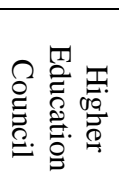 & 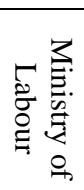 & 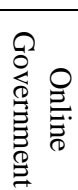 \\
\hline $\begin{array}{c}\text { Font } \\
\text { Adjustment }\end{array}$ & 12.5 & 0 & 0 & 12.5 & 12.5 \\
\hline $\begin{array}{c}\text { Language } \\
\text { Support }\end{array}$ & 12.5 & 12.5 & 12.5 & 12.5 & 12.5 \\
\hline $\begin{array}{c}\text { Print } \\
\text { Version }\end{array}$ & 12.5 & 12.5 & 0 & 0 & 0 \\
\hline $\begin{array}{l}\text { Mobile App. } \\
\text { Support }\end{array}$ & 0 & 12.5 & 0 & 0 & 12.5 \\
\hline $\begin{array}{c}\text { Color } \\
\text { Standards }\end{array}$ & 0 & 0 & 0 & 0 & 0 \\
\hline $\begin{array}{c}\text { B/W } \\
\text { Version }\end{array}$ & 12.5 & 0 & 12.5 & 12.5 & 12.5 \\
\hline $\begin{array}{c}\text { Accessibility } \\
\text { Help }\end{array}$ & 12.5 & 0 & 0 & 0 & 12.5 \\
\hline Audio & 12.5 & 0 & 0 & 0 & 0 \\
\hline $\begin{array}{c}\text { Total } \\
\text { Criteria }\end{array}$ & 75 & 50 & 25 & 37.5 & 62.5 \\
\hline Total Score & \multicolumn{5}{|c|}{250} \\
\hline
\end{tabular}

\section{FINDINGS}

The study is a comparison of the level of achievement by each country from points allocated. The research also ranks countries in the Middle East by the level of e-government development and utilizes the manual and automated testing to determine if a specific criterion was met.

\subsection{Manual Testing Evaluation}

The chart in figure 4 below displays the results of each country based on the manual criteria; font adjustment; language support; print version; mobile app. Support; color standards; disable page color (B/W version); accessibility help and audio. Results from the chart showed that Yemen scored low in majority of the criteria, with the exception of $100 \%$ in disable page color and $20 \%$ in language support as only one of its websites supports the English language standard. Similarly, Turkey also scored low in most of the standards but scored $60 \%$ in disable page color and $40 \%$ in language support. With regards to font adjustment, print version, color 
standards, accessibility help and audio, all five websites in Kuwait scored high but scored below average in font adjustment.

Israel performed much better and scored above average in more than half of the benchmarks with the exception of mobile app support, color standards, accessibility help and audio with a score of less than average. Similarly, Egypt achieved a higher percentage in more than half of the criteria, while scoring low in print version, color standards and audio. Additionally, Lebanon scored high in half of the criteria but scored $0 \%$ in color standards, accessibility and audio. Qatar achieved a high percentage score in more than half of the standards and scored $0 \%$ in print version, color standards and audio. Government websites of Iraq achieved high scores in half of the criteria but scored low in print version, mobile app support, accessibility and audio.

The governmental websites of Iran and Syria scored a high percentage in half of their criteria. However, both countries scored low in mobile app support, color standards, accessibility help and audio. In addition, both Palestine and Jordan scored high in half of the benchmarks but scored low in print version, color standards, accessibility and audio. While Cyprus scored high in half of the criteria, it scored low in font adjustment, mobile app support, color standards and audio. UAE governmental websites achieved the highest scores in most of the criteria except for mobile app support and disable page color where it scored low percentage. The websites of Oman passed all the set standards.

The color standard was the only benchmark where the Bahrain government websites scored a high percentage while scoring low in all the remaining. In Saudi Arabia, only a single government website scored a high percentage in print version and color standards, while the remaining four websites scored an average of $20 \%$.

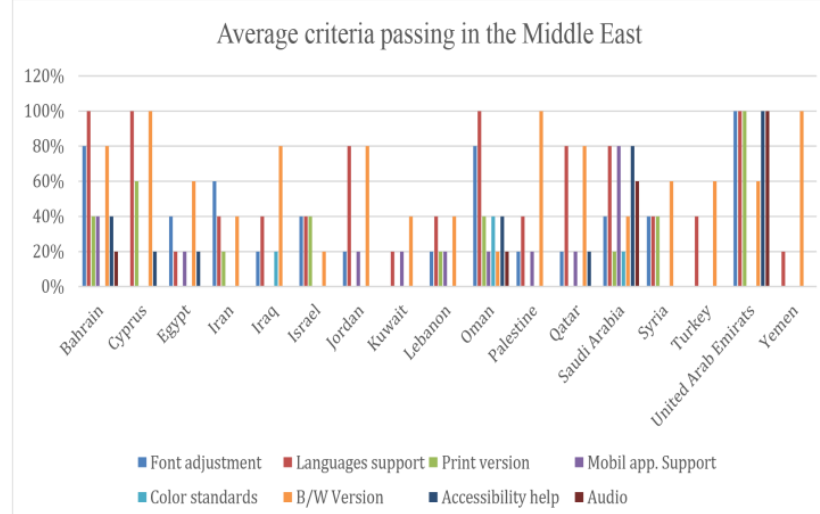

Fig.4: The evaluation findings for Middle East countries based on the manual criteria

The chart in figure 5 below presents the ranking of the countries that scored high percentage in majority of the set benchmarks. The highest is UAE which achieved $350 \%$ out of a possible $500 \%$, Saudi Arabia achieved more than half with a score of $262.5 \%$ while Bahrain scored $250 \%$ and is closely followed by Oman with a score of $237.5 \%$. Cyprus achieved less than half of the total score with $175 \%$, performing better than Qatar and Jordan which scored $137.5 \%$ and $125 \%$ respectively. Palestine and Syria both achieved scores of $112.5 \%$ while Egypt, Iran and Iraq all scored $100 \%$. Israel and Lebanon both scored $87.5 \%$, Yemen scored $75 \%$, while both Kuwait and Turkey achieved the lowest score of $62.5 \%$.

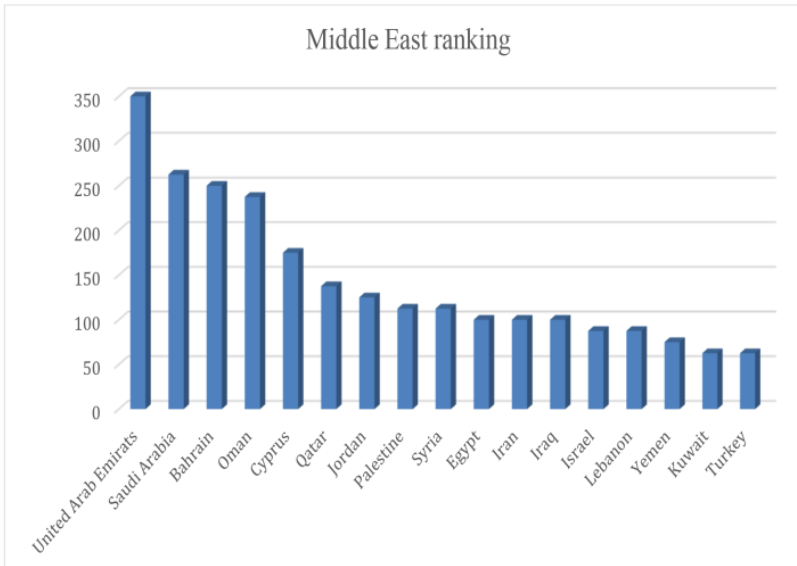

Fig.5: Ranking of Middle East countries based on the manual evaluation criteria results.

\subsection{Automated Evaluation Testing}

As shown in table 3 below, the results of the standards and accessibility automated test for all 17 countries in the Middle East. Only countries with a score of 1 passed any of the criteria.

Table 3. Results of Automated Testing

\begin{tabular}{|c|c|c|c|}
\hline S/N & E-Government & Accessibility & Standards \\
\hline $\mathbf{1}$ & Bahrain & 1 & 1 \\
\hline $\mathbf{2}$ & Cyprus & 0 & 0 \\
\hline $\mathbf{3}$ & Egypt & 1 & 1 \\
\hline $\mathbf{4}$ & Iran & 1 & 0 \\
\hline $\mathbf{5}$ & Iraq & 1 & 1 \\
\hline $\mathbf{6}$ & Israel & 0 & 0 \\
\hline $\mathbf{7}$ & Jordan & 0 & 0 \\
\hline $\mathbf{8}$ & Kuwait & 1 & 1 \\
\hline $\mathbf{9}$ & Lebanon & 0 & 0 \\
\hline $\mathbf{1 0}$ & Oman & 0 & 0 \\
\hline $\mathbf{1 1}$ & Palestine & 0 & 0 \\
\hline $\mathbf{1 2}$ & Qatar & 0 & 0 \\
\hline $\mathbf{1 3}$ & Saudi Arabia & 1 & 1 \\
\hline $\mathbf{1 4}$ & Syria & 0 & 0 \\
\hline $\mathbf{1 5}$ & Turkey & 0 & 0 \\
\hline $\mathbf{1 6}$ & United Arab Emirates & 0 & 0 \\
\hline $\mathbf{1 7}$ & Yemen & 0 & 0 \\
\hline \multicolumn{4}{|c|}{ Max $=1$ pass } \\
\hline
\end{tabular}

The study reveals that Bahrain, Egypt, Iraq, Kuwait and Saudi Arabia all passed both criteria on accessibility and standards, however, Iran only passed the accessibility criterion in one out of five of its websites as presented in table 3 above.

At the end of the study, the research should be able to answer the two questions stated.

The first question: If countries in the Middle East meet the criteria used to evaluate them in both automated and the manual testing?

As there is no direct answer because the outcome qualifies for both yes and no. This is because less than a quarter of all the countries scored high percentages in at least half of the total criteria in the automated testing; UAE, Saudi Arabia, Bahrain and Oman achieved the highest scores. 
The second question: Why these countries marginally passed only some of the criteria?

The countries that passed only some of the set benchmark is as a result of less awareness on disability in these countries in comparison to developed nations and this is reflected on their websites which do not provide accessibility support for users with disability. Additionally, users experience language difficulties while trying to locate resources on web accessibility. Governmental websites in Yemen, Iraq and Turkey do not have features for e-government services. Turkey, in particular, does not provide an online government portal for its citizens. To this end, it is essential to create awareness on disability and needs of such users while enhancing online accessibility.

This study also reveals that the automated testing should not be considered as a trusted tool for evaluating websites as indicated in the results; in the automated testing Iraq, Iran and Egypt all scored high in both accessibility and standards, conversely, they scored the lowest points in the manual testing.

\section{CONCLUSION}

The research questions of this study were formulated to determine if governmental websites in the Middle East met the accessibility criteria or not and to assess their level of implementation. The results from the manual and the automated testing reveal different answers. In the case of the automated testing, Bahrain, Oman, Saudi Arabia and UAE which constitute less than a quarter of the countries in the Middle East scored very high in majority of the criteria. One of the reasons is due to higher levels of awareness among government and citizens of these countries. Another reason is due to stale governments in these countries. However, these countries scored low in the automated criteria and these contrasts prompted the researchers to conclude that the automated testing should not be considered as a trusted method for evaluating websites. Furthermore, there are limited web resources on web accessibility in languages such as Arabic or Hebrew.

In conclusion, the study reveals that countries such as Israel, Jordan, Iraq and Yemen among others scored very low in most of the criteria as a result of low awareness of people living with disabilities as featured on their government websites and online portals.

\section{ACKNOWLEGEMENTS}

The authors would like to thank Khazar University for their support.

\section{REFERENCES}

[1] Abanumy, A., Al-Badi, A., and Mayhew, P. 2005. EGovernment Website accessibility: In depth evaluation of Saudi Arabia and Oman,The Electronic Journal of eGovernment, 3(3), 99-106.

[2] Kuzma, J. 2010. Global E-government web accessibility: a case study.

[3] Al-Khalifa, H. S. 2012. The accessibility of Saudi Arabia government Web sites: an exploratory study, Universal Access in the Information Society, 11(2), 201-210.

[4] W3C, Long Description of W3C10 Timeline Graphic, http://www.w3.org/2005/01/timelines/description. 2005.
[5] Rehabilitation Act 1973, s508, https://www.section508.gov/manage/laws-and-policies. 1973.

[6] BCS: The Chartered Institute for IT (BS 8878). 2010. Web Accessibility - Code of Practice, https://www.bcs.org/upload/pdf/bs8878-response.pdf.

[7] Henry, S. L. 2005. Introduction to Web Accessibility, https://www.w3.org/WAI/intro/accessibility.php.

[8] Akgül, Y., and Vatansever, K. 2016. Web Accessibility evaluation of Government websites for people with disabilities in Turkey, Journal of Advanced Management Science, 4(3).

[9] Lee, B. T., and Fischetti, M. 1999. Weaving the Web: The Original Design and Ultimate Destiny of the World Wide Web by Its Inventor.

[10] Dardailler, D. 2009. WAI early days, http://www.w3.org/WAI/history.

[11] Henry, S. L., and McGee, L. 2016. Accessibility, http://www.w3.org/standards/webdesign/accessibility.

[12] Brewer, J. 2003. Web accessibility highlights and trends, SIGCAPH Computing Physics Handicap. 76, 15-16.

[13] Updike, J., and McCarthy, J. 2006. Web Accessibility for People with Communication Disorders, ASHA Leader, 11(13), 34-35.

[14] Kumar, R. 2011. Research Methodologies: a step-by-step guide for beginners.

[15] Kurfal, M., Arifoğlu, A., Tokdemir G., and Paçin, Y. 2017. Adoption of e-government services in Turkey, Computers in Human Behavior, 66, 168-178.

[16] PowerMapper Software, Sortsite Tool, https://www.powermapper.com. 2018.

[17] Lallmahomed, M. Z .I., Lallmahomed, N., and Lallmahomed, G. M. 2017. Factors influencing the adoption of e-Government services in Mauritius, Telematics and Informatics, 34(4), 57-72.

[18] Toledo-Pereyra, L. H. 2012. Research Design, Journal of Investigative Surgery, 25(5), 279-280.

[19] Al-Mourad, B., and Kamoun F. 2013. Accessibility Evaluation of Dubai e-Government Websites: Findings and Implications, Journal of E-Government Studies and Best Practices, 1-15.

[20] Al-Athmay, A. 2013. E-governance in Arab countries: status and challenges, Global Journal of Business Research, 7(5).

[21] Basamh, S. S. Qudaih, H. A., and Suhaimi, M. A. 2014. E-Government Implementation in the Kingdom of Saudi Arabia: An Exploratory Study on Current Practices, Obstacles \& Challenges, International Journal of Humanities and Social Sciences, 4(2), 296-30.

[22] Cailliau, R. 1995. A Little History of the World Wide Web, http://www.w3.org/History.html. 